\title{
O DESIGN PARA EMOÇÃO NA EXPERIÊNCIA DE ECONOMIZAR RECURSOS FINANCEIROS: IDENTIFICAÇÃO DE CONCERNS CONFLITANTES
}

\author{
Tania Grigoletto \\ UNISINOS \\ taniagri@yahoo.com \\ Filipe Campelo Xavier da Costa \\ UNISINOS \\ fcampelo@unisinos.br \\ Celso Carnos Scaletsky \\ UNISINOS \\ celsos@unisinos.br
}

Resumo: Este artigo apresenta uma reflexão teórica e resultados de uma pesquisa acerca de como o design, a partir de uma perspectiva projetual com foco nas emoções, pode auxiliar na identificação e conciliação de concerns conflitantes presentes na experiência de economizar recursos financeiros. A pesquisa é fundamentada na teoria dos appraisals, oriunda da psicologia cognitiva, na qual três variáveis fazem parte do processo de desencadeamento das emoções com o produto: o interesse ou demanda das pessoas (concern), o estímulo (produto ou serviço) e a avaliação (appraisal). Vale observar que os concerns que orientam as interações cotidianas, muitas vezes, são conflitantes, como a gestão das finanças pessoais. Para tanto, realizou-se uma pesquisa direta com usuários para identificação dos concerns envolvidos no ato de poupar, a partir de seis entrevistas em profundidade, com casais residentes em Porto Alegre. Com os dados gerados, foram sinalizados os principais conflitos e construído um perfil de concerns. Também foram destacados concerns relevantes para a ação projetual.

Palavras-chave: design para emoção, concerns conflitantes, experiência, poupança

Abstract: This paper presents a theoretical reflection and results of a research on how the design, from a projectual perspective focused on emotions, can help identify conflicting concerns present in the experience of saving financial resources. The research is based on the appraisals theory, derived from cognitive psychology of which three variables are considered: the interest or demands of people (concerns), the stimulus (product or service) and the evaluation (appraisal). The concerns that guide the everyday interactions, are often conflicting and more present in the personal finance management. A direct survey was conducted with users in 
order to identify the concerns involved in the act of saving, through interviews with six couples living in Porto Alegre. With the data generated, was built a list of concern and flagged major conflicts. Also were highlighted concerns relevant to the projectual action.

Keywords: emotional design, conflicting concerns, experience, savings

\section{INTRODUÇÃO}

A sociedade contemporânea é movida por altos níveis de consumo e concorrência. O consumo está atrelado à liberdade de escolha para aquisição de bens, serviços e experiências. Nesse sentido, é produtor de status, fonte de prazer e felicidade (BARBOSA, 2004). Carù e Cova (2007) afirmam que, progressivamente, o comportamento do consumo distancia-se do conceito tradicional voltado ao valor de uso dos produtos para tornar-se uma atividade que envolve uma produção de significados e vivências simbólicas.

Nesse sentido, ofertar produtos e/ou serviços atrativos exigem a compreensão do contexto e das expectativas dos usuários, assim como, requerem uma estratégia por trás de suas concepções, capaz de torná-los desejáveis e, portanto, competitivos. Essas questões são comuns ao conceito de design, definido por Buchanan (2001, p. 9) como "o poder humano de conceber, planejar e fazer produtos que servem aos seres humanos no cumprimento de seus propósitos individuais e coletivos". O autor sugere um olhar para o lado interno do produto, não no sentido físico e sim no sentido da experiência. Assim, deve-se considerar como as pessoas interagem com os produtos e como os usam na forma de uma influência mediadora em suas interações com outras pessoas e seus ambientes sociais e naturais (BUCHANAN, 2001).

Outros autores, como Cardoso (2004) e Verganti (2008), também entendem que o design lida não só com a funcionalidade de um produto, mas também com o seu valor simbólico e emocional. Nesse sentido, a compreensão do design vai além da construção de artefatos fabris, pois trata-se da aplicação do design tanto a bens materiais como imateriais, nos quais se incluem serviços, experiências, narrativas, identidades de marcas, interfaces, entre outros artefatos passíveis de projetação.

O que está por trás dessa discussão é a ampliação do produto em si para um sistema-produto-serviço que, segundo Meroni (2008), funciona como uma estratégia integrada de design, orientada para a produção de soluções que misturam produtos, serviços, comunicação e as pessoas. Nesse sentido, Zurlo (2010) e Meroni (2008) apontam que o design é estratégico quando atua visando a gerar sentido e valor aos diversos atores envolvidos no processo, em especial, aos usuários.

Para isso, é fundamental entender as pessoas. É necessário compreender as experiências dos usuários e as formas de representar as dimensões dessa experiência (SURI, 2003). Nesse viés, entra em jogo a capacidade do design de resolver problemas complexos, buscando embasamento e inspiração em outros campos do conhecimento para criar artefatos capazes de produzirem significados e evocarem emoções.

Buchanan (1985) foi um dos primeiros autores de design a incluir, em seu discurso, a emoção. Ele aborda o desafio do designer em moldar uma linha de pensamento que influencia a atitude ou o comportamento do consumidor em relação 
a um produto, de maneira a persuadi-lo, convencendo-o de que aquele produto é emocionalmente desejável e valoroso para a sua vida.

O design para emoção consolida-se, a partir dos anos 90, como um campo que reúne conhecimentos oriundos do design e da psicologia. Sua atuação está relacionada à moderação das experiências emocionais desejáveis pelas pessoas, pois refere-se à profissionalização do projetar, com intuito explícito de despertar ou evitar determinadas emoções (DEMIR et. al., 2009). Dentre as diversas abordagens que visam a compreender as diferentes respostas emocionais, resultantes da interação de usuários com produtos e serviços, a presente pesquisa fundamenta-se nos pressupostos desenvolvidos pelo estudo de Desmet (2002).

\section{Teoria dos appraisals e os concerns conflitantes}

Desmet (2002) sugere que as emoções surgem por meio de uma avaliação (appraisal) que o usuário tem ao interagir com um produto. Ele propõe um modelo baseado em uma teoria cognitiva das emoções, denominada Appraisal Theory. Em sua essência, a teoria do appraisal discorre sobre a possibilidade das emoções serem elucidadas por meio de avaliações ou julgamentos (appraisals) de situações ou experiências, tornando possível descrever e diferenciar as emoções (SCHERER et. al., 2001). Desmet (2002) defende uma relação de causalidade entre uma avaliação pessoal (appraisal) e uma emoção, pois as respostas emocionais não são, necessariamente, desencadeadas por estímulos ou por produtos, mas decorrentes de avaliações individuais, baseadas em atributos e interesses próprios. Como pode ser observado na figura 1, o modelo apresenta as três variáveis que fazem parte do processo de compreensão das emoções: appraisals (avaliações), concerns (disposições internas dos indivíduos responsáveis pelos desejos e anseios em relação aos produtos) e produtos (estímulos). Cabe ressaltar que, apesar de utilizar o termo "produto", Desmet (2007) defende que essa variável se refere a uma dimensão mais ampla do que um artefato físico.

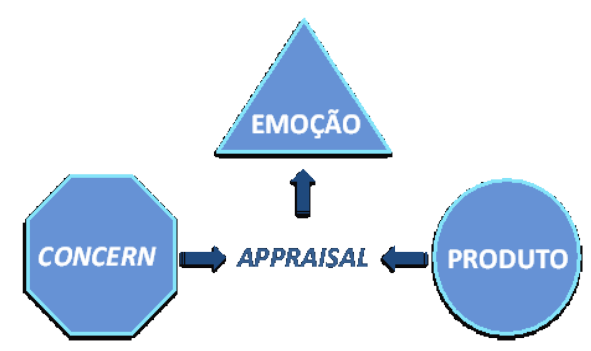

Figura 1 - Modelo básico de compreensão sobre as emoções em relação a produtos. Fonte: Adaptado de Desmet (2002).

A variável concern refere-se a interesses, objetivos, demandas, padrões e atitudes individuais que orientam as interações cotidianas (FRIJDA, 1986). Um concern pode ser qualquer objetivo ou motivo que um indivíduo tem na vida como, por exemplo, alcançar status ou sentir-se seguro (FRIJDA, 1989). Nesse sentido, Desmet (2002) compreende que um concern é responsável pela determinação do nível de significância e valor de um estímulo para cada indivíduo. Assim, os concerns moldam as avaliações (appraisals) dos usuários, funcionando como uma avaliação automática do efeito de um produto no bem-estar de alguém (DESMET; HEKKERT, 2009). 
A avaliação de um estímulo pode ser favorável ou não, dependendo dos concerns de cada pessoa. Nesse sentido, a identificação e compreensão dos concerns dos indivíduos permitiriam o desenvolvimento de produtos orientados à evocação de determinadas avaliações e, consequentemente, de emoções desejadas (DESMET, 2002; DEMIR, et. al. 2010).

Desmet (2007) propôs um modelo de categorização, classificando os concerns em três categorias distintas - atitudes, objetivos e padrões -, e cruzando-as com três níveis de relações homem-produto - consequência, uso e produto. Em 2010, Desmet sugere um modelo de categorização a partir dos appraisals, considerando que estes são um parâmetro chave para determinar se um produto evoca uma emoção. Para isso, o autor identificou três principais tipos de avaliação (appraisal) - utilidade, agradabilidade e legitimidade -, fazendo o cruzamento com três classes de estímulos: autofoco, foco na atividade e foco no produto.

Ambos os modelos resultam em uma matriz com nove fontes de emoção com produtos. Ao analisar os dois quadros propostos por Desmet (2007 e 2010), é possível relacionar as avaliações (appraisals) chaves com os três tipos de concerns, respectivamente, como sugerem Ozkaramanli e Desmet (2012) no seguinte quadro:

Quadro 1 - Nove fontes de emoção com produto.

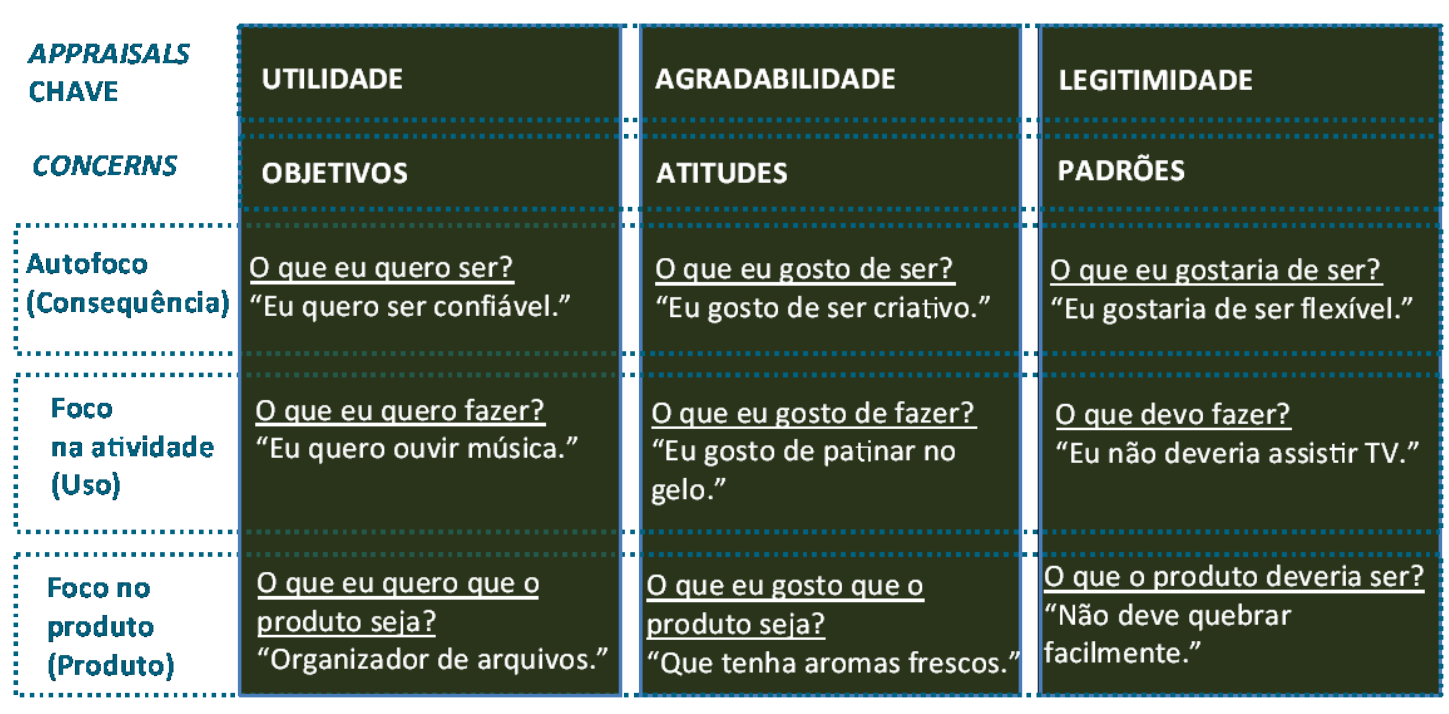

Fonte: Desmet (2007 e 2010), adaptado e traduzido pela autora.

Desmet e outros pesquisadores, como Demir e Ozkaramanli (2010), sugerem uma metodologia para a análise dos concerns e aplicam um processo baseado em quatro etapas: temática de design, perfil de concerns, perfil de produto e o projeto de produto.

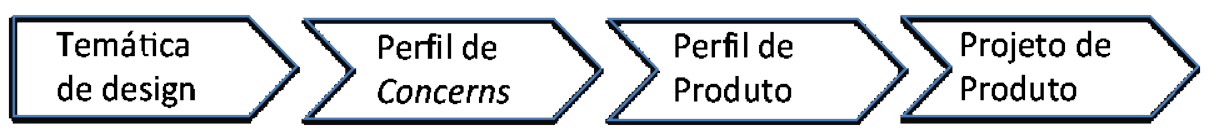

Figura 2 - As quatro etapas projetuais

Fonte: Adaptado de Desmet (2007), Demir, et. al. (2010) e Desmet (2010).

De acordo com Desmet (2010), a primeira etapa, temática de design, consiste na identificação do âmbito funcional do produto a ser desenvolvido, do grupo e 
população de usuários envolvidos, além do cenário e contexto em que a interação ocorrerá. A segunda etapa, perfil de concerns, é considerada uma das etapas mais críticas do processo, pois trata da identificação e levantamento dos concerns e gatilhos responsáveis pelo desencadeamento das emoções dos indivíduos. Para Demir et al. (2010), esta fase apresenta uma significativa dificuldade para os designers que precisam acessar, identificar e formular concerns que sejam relevantes para o projeto e, consequentemente, para os indivíduos. Na etapa de levantamento, são utilizadas técnicas exploratórias com o intuito de obter o máximo de detalhes sobre um determinado concern por meio de perguntas-chave a respeito da percepção emocional do entrevistado sobre uma determinada situação. Identificados os concerns, eles devem ser classificados de acordo com suas características para que se possa elaborar o modelo de perfil de concerns a partir da compilação dos pontos mais relevantes, obtidos na fase de levantamento. Na terceira etapa, o designer deve identificar quais são e como serão abordados os gatilhos emocionais, visando a desenvolver soluções coerentes com os desejos e interesses demonstrados no perfil de concern. Na última etapa, os autores propõem o desenvolvimento de um produto que se enquadre nas referências obtidas nas etapas anteriores, objetivando, assim, chegar a uma solução que consiga despertar ou evitar determinadas emoções nos usuários-alvo (DEMIR, et. al. 2010).

A partir dessas etapas projetuais, vale ressaltar a importância dos concerns nesse processo e considerar que estes, além de serem individuais, podem ser divergentes. Conforme Ozkaramanli e Desmet (2012), concerns conflitantes são inerentes à natureza humana e, portanto, são uma parte inevitável de qualquer caso de design centrado no usuário. Os autores observam que o alcance de um objetivo perseguido torna-se mais provável quando ele estiver alinhado a padrões e atitudes. Desse modo, quando os concerns são harmônicos e despertam o mesmo tipo de emoção, tendem a potencializar a atividade e o prazer obtido através destes. Entretanto, o desalinhamento entre padrões e atitudes dificulta o progresso do objetivo, levando a concerns e emoções conflitantes mistas. Assim, em uma situação em que os concerns forem desarmônicos, opostos ou, ainda, conflitantes, o indivíduo será exposto a um cenário em que a tomada de decisão será baseada na eliminação ou superação de uma das possibilidades, provocando sensações indesejáveis, ou até mesmo, negativas.

Os concerns em conflito são mais evidentes em alguns domínios como, por exemplo, na relação das pessoas com a gestão do seu dinheiro, que é o tema deste artigo. O estudo Retratos da Sociedade Brasileira: Inclusão Financeira, da CNI/Ibope, de junho de 2012, revela que apenas $31 \%$ dos brasileiros fazem algum tipo de reserva de dinheiro. Em contrapartida, 59,6\% das famílias brasileiras têm algum tipo de dívida, segundo Pesquisa de Endividamento e Inadimplência do Consumidor (PEIC), apurada pela CNC, em abril de 2016. Esses dados demonstram que as pessoas têm dificuldades de fazer sua gestão financeira e, consequentemente, de economizar/poupar. Diversos fatores, como condições de emprego e renda, nível educacional e sociocultural, influenciam essa situação, demonstrando tratar-se de um problema complexo e que atinge um número grande de brasileiros.

\subsection{Poupança sob a perspectiva do indivíduo}

Para a melhor compreensão do tema poupança interessam as visões que 
consideram as diferenças individuais. Nesse sentido, o pensamento de Katona (1975), importante referência da psicologia econômica, contribui ao afirmar que consumo e poupança dependem de dois fatores: a capacidade (ability) para poupar e a vontade (willingness) de poupar. O autor considera as atitudes, motivos e expectativas individuais ao pensar na formação de poupança e não somente a visão macroeconômica.

Investigações sobre a poupança também têm se pautado em torno da motivação e escolha intemporal ${ }^{1}$, em que o elemento incerteza ocupa lugar decisivo. 0 indivíduo pode ficar diante de uma escolha intemporal: abrir mão de satisfazer um impulso para gastar já, ou adiar essa satisfação em nome de uma gratificação futura maior (FERREIRA, 2008).

Outro aspecto, considerado o principal para prever o comportamento de poupar, é a hipótese de ciclo de vida comportamental. Considerando isso, Shefrin e Thaler (1988), estudiosos da economia e finanças comportamentais, propuseram três alterações nessa hipótese em relação ao modelo postulado pela economia clássica:

a) conceito de autocontrole - mesmo as pessoas estando determinadas a poupar o dinheiro que sobra, nem sempre o fazem de fato, pois a recompensa imediata para gastar é geralmente maior do que a recompensa imediata para poupar.

b) questionamento do conceito de fungibilidade - os autores afirmam que a fonte de qualquer quantia de dinheiro pode afetar a facilidade com que ele é gasto. Assim, uma gratificação extra recebida, por exemplo, pode ser gasta mais facilmente do que aquela quantia que faz parte do salário regular.

c) Framing (ou enquadramento) - processo de alocar recursos financeiros em distintas contas mensais, o que expressaria algo como limitações de percepção. Um exemplo é a opção de uma pessoa fazer um consórcio para conseguir adquirir uma reserva.

Estudos recentes sobre a relação das pessoas com o dinheiro confirmam alguns desses conceitos e apontam outros aspectos importantes. Um exemplo é a pesquisa conduzida por Nyhus (2002), que investigou as questões financeiras no âmbito familiar de 1.500 domicílios na Holanda. Como resultado, destacou-se a dificuldade das pessoas para conciliar interesses de curto e longo prazo, sendo os objetivos de poupança de longo prazo mais árduos de atingir para aqueles que se mostram mais propensos às tentações de consumo.

Outro exemplo, é o estudo de Meirelles (2012), realizado no Brasil por meio de uma survey que contou com a participação de 600 pessoas com idade entre 18 e 75 anos, de classe média e média alta. A pesquisa constatou que os padrões de uso do dinheiro são afetados pelos períodos da vida adulta, pelo sexo e estado civil, bem comopela influência e educação herdados dos pais (MEIRELLES, 2012). Quanto aos valores e crenças, Meirelles observou que os participantes não demonstraram uma preocupação constante com o dinheiro, pois não são arrojados em seus investimentos e buscam segurança (um alto índice de pessoas comprariam um imóvel caso ganhassem um milhão de reais); gastam com quem se gosta - família e amigos (muitas

\footnotetext{
${ }^{1}$ Escolha intemporal é um campo que estuda o valor relativo que as pessoas atribuem a recompensas em diferentes pontos do tempo. Os resultados geralmente apontam que as pessoas são predispostas a preferir recompensas no presente e tendem a descontar o futuro (ÁVILA e BIANCHI, 2015).
} 
vezes parcelando as compras); e, ao mesmo tempo, não expõem suas contas. Com isso, a pesquisa demonstrou que eles usam o dinheiro para viver bem o presente, optando por bens que ofereçam conforto e qualidade de vida.

Diante do panorama apresentado, observa-se a complexidade do tema e o impacto que ele tem na vida das pessoas. Também fica evidente a importância de compreender as peculiaridades e os concerns conflitantes que envolvem a relação com as finanças pessoais. Assim, considera-se que o design, por sua capacidade de atuar no entendimento de realidades complexas como essa, pode contribuir para gerar uma experiência emocional positiva entre poupadores. Seguindo as etapas do processo citadas anteriormente, este estudo foca na definição da temática e na construção de um perfil de concerns.

\section{TEMÁTICA E PERFIL DE CONCERN}

Para compreender os concerns e os conflitos nessa temática, além da pesquisa bibliográfica apresentada, foram realizadas seis entrevistas em profundidade, com roteiro semi-estruturado, na residência dos pesquisados. Ao todo, foram entrevistados seis casais residentes em Porto Alegre, com idade entre 30 e 40 anos, sendo três pertencentes à classe $A$ (renda a partir de $R \$ 11.262,00$ ) e três, à classe $C$ (renda de $R \$$ $2.005,00$ a $R \$ 8.640,00)^{2}$. Foram excluídas as classes $D$ e E por possuírem um nível de renda muito baixo, o que impacta diretamente na possibilidade de poupar. Os entrevistados pertencem ao início da vida adulta (20-40), ciclo que representa o período em que a vida financeira se constrói e as bases para o futuro são determinadas (PAPALIA et. al., 2010). Da mesma maneira, optou-se por entrevistar casais pelo fato do planejamento financeiro e os projetos de vida dizerem respeito ao núcleo familiar e não somente a um dos membros.

O roteiro iniciou por questões mais amplas: Quem é você? Fale-me sobre você; Conte-me sobre suas aspirações/futuro. As perguntas posteriores, dirigiram-se à esfera financeira: Como é seu comportamento ao comprar algo? Como você gerencia seus gastos e seu dinheiro? Que ênfase você coloca no planejamento das finanças pessoais? $\mathrm{O}$ que você considera um investimento? Esses temas foram dirigidos tanto ao homem como à mulher, buscando entender as perspectivas de cada um, assim como, os pontos de divergência e convergência entre eles.

As entrevistas foram transcritas na íntegra e os dados foram analisados por meio de Análise de Conteúdo. Foram selecionadas todas as citações dos usuários pertinentes à temática investigada. Posteriormente, as respostas dos pesquisados foram interpretadas com o intuito de selecionar declarações representativas das três categorias de concerns pré-definidas de acordo com a revisão da literatura: objetivos/metas, atitudes e padrões/normas. Estas foram cruzadas com os três tipos de estímulos em relação ao produto (poupança): autofoco (consequência), foco na atividade (uso) e foco no produto (produto). Essas informações foram organizadas no quadro a seguir e formam o perfil de concerns sobre a vida financeira dos pesquisados.

\footnotetext{
2 Dados obtidos no site da SECRETARIA DE ASSUNTOS ESTRATÉGICOS DA PRESIDÊNCIA DA REPÚBLICA. A Classe Média Brasileira. Nov. 2014.
} 
Quadro 2 . Perfil de concerns (modificados a partir das nove fontes de emoção com produto).

\begin{tabular}{|c|c|c|c|}
\hline & $\begin{array}{l}\text { Avaliação de utilidade } \\
\text { (objetivos/metas) }\end{array}$ & $\begin{array}{c}\text { Avaliação de agradabilidade } \\
\text { (atitudes) }\end{array}$ & $\begin{array}{c}\text { Avaliação de legitimidade } \\
\text { (padrōes/normas) }\end{array}$ \\
\hline \multirow{3}{*}{$\begin{array}{c}\text { Autofoco } \\
\text { (consequência) }\end{array}$} & & Eu gosto de gastar. 2 & $\begin{array}{l}\text { Eu gostaria de não ser tão } \\
\text { compulsiva e gastar tanto } \\
\text { dinheiro. } 6\end{array}$ \\
\hline & $\begin{array}{l}\text { Quero muito dar alguma coisa } \\
\text { para quando minha filha tiver } \\
18 \text { anos conseguir andar. } 1\end{array}$ & $\begin{array}{l}\text { Nós gostamos de ter uma } \\
\text { ligação leve com o dinheiro } \\
\text { por isso nos cercamos de uma } \\
\text { segurança. } 8\end{array}$ & $\begin{array}{l}\text { Eu não deveria esbanjar. } \\
\text { Deveria dar mais valor ao meu } \\
\text { dinheiro e pensar no futuro. } 2\end{array}$ \\
\hline & & & $\begin{array}{l}\text { Eu gostaria de investir na } \\
\text { minha formação. } 4\end{array}$ \\
\hline \multirow{8}{*}{$\begin{array}{l}\text { Foco na } \\
\text { atividade } \\
\text { (uso) }\end{array}$} & $\begin{array}{l}\text { Não queremos perder horas } \\
\text { de sono porque investimos } \\
\text { mal o dinheiro por isso } \\
\text { preferimos ganhar um pouco } \\
\text { menos. } 7\end{array}$ & $\begin{array}{l}\text { Eu gosto de manter minha } \\
\text { planilha financeira atualizada } \\
\text { para manter o controle das } \\
\text { contas e ver como para } \\
\text { economizar. } 1\end{array}$ & $\begin{array}{l}\text { Eu gostaria de ter concluído } \\
\text { uma formação superior, mas } \\
\text { não consegui por falta de } \\
\text { condições financeiras. } 4\end{array}$ \\
\hline & $\begin{array}{l}\text { Nós queremos ter um negócio } \\
\text { organizado para ter uma } \\
\text { renda e garantir uma vida } \\
\text { confortável. } 7\end{array}$ & $\begin{array}{l}\text { Eu gosto de pensar no futuro } \\
\text { e guardar um percentual do } \\
\text { que ganho. } 10\end{array}$ & $\begin{array}{l}\text { Eu devo economizar todo } \\
\text { mês, mesmo que seja pouco e } \\
\text { mesmo que implique em abrir } \\
\text { de algumas coisas. } 10\end{array}$ \\
\hline & $\begin{array}{l}\text { Não queremos recorrer a } \\
\text { financiamentos em bancos } \\
\text { para evitar juros altos. } 8\end{array}$ & $\begin{array}{l}\text { Eu gosto de comprar aquilo } \\
\text { que gostei independente do } \\
\text { preço. } 2\end{array}$ & $\begin{array}{l}\text { A gente deveria estar } \\
\text { guardando dinheiro para } \\
\text { melhorar de vida. } 1\end{array}$ \\
\hline & & $\begin{array}{l}\text { Eu gosto de pensar que a cada } \\
\text { ano você pode adquirir } \\
\text { alguma coisa e em cinco anos } \\
\text { você pode ter uma casa na } \\
\text { praia sem esforço. } 1\end{array}$ & $\begin{array}{l}\text { Eu deveria comprar uma casa } \\
\text { ou apartamento porque é um } \\
\text { bem que é teu. É um bom } \\
\text { investimento. } 1\end{array}$ \\
\hline & $\begin{array}{l}\text { Queremos que a nossa apo- } \\
\text { sentadoria seja de investi- } \\
\text { mentos em imóveis ou pou- } \\
\text { pança porque não queremos } \\
\text { pagar taxas e juros por uma } \\
\text { previdência privada. } 7\end{array}$ & $\begin{array}{l}\text { Eu gosto de ter contas e a } \\
\text { administração do dinheiro } \\
\text { separadas (esposa e marido) } \\
\text { para não ficar histérica com os } \\
\text { gastos dele. } 10\end{array}$ & $\begin{array}{l}\text { Eu deveria seguir o exemplo } \\
\text { do meu marido na forma de } \\
\text { controlar o dinheiro porque } \\
\text { do jeito dele dá certo e do } \\
\text { meu não. } 2\end{array}$ \\
\hline & $\begin{array}{l}\text { Eu quero que meu filho tenha } \\
\text { uma poupança. } 10\end{array}$ & $\begin{array}{l}\text { Nós gostamos de investir em } \\
\text { viagem porque dá energia, um } \\
\text { novo gás. } 8\end{array}$ & $\begin{array}{l}\text { Deveria ganhar mais pra po- } \\
\text { der buscar o que almejo. } 1\end{array}$ \\
\hline & & $\begin{array}{l}\text { Não gosto de dívidas por isso } \\
\text { pago tudo religiosamente em } \\
\text { dia para não pagar juros. } 11\end{array}$ & $\begin{array}{l}\text { Eu deveria usar melhor minha } \\
\text { planilha de despesas e anotar } \\
\text { cada gasto. } 6\end{array}$ \\
\hline & $\begin{array}{l}\text { Quero juntar R\$10 mil pra } \\
\text { comprar um carro e R\$20 mil } \\
\text { pra dar entrada num imóvel } \\
\text { para sair do aluguel. } 2\end{array}$ & $\begin{array}{l}\text { Eu gosto de colocar as contas } \\
\text { no débito para ter mais } \\
\text { controle. } 6\end{array}$ & $\begin{array}{l}\text { Eu deveria manter algum } \\
\text { investimento, mas não } \\
\text { consigo porque não tenho } \\
\text { controle. } 3\end{array}$ \\
\hline \multirow{3}{*}{$\begin{array}{l}\text { Foco no } \\
\text { produto } \\
\text { (produto) }\end{array}$} & $\begin{array}{l}\text { Quero ganhar dinheiro, mas } \\
\text { não quero correr riscos. } 10\end{array}$ & & $\begin{array}{l}\text { A poupança deveria render } \\
\text { mais. } 6\end{array}$ \\
\hline & $\begin{array}{l}\text { Manter uma reserva é ter uma } \\
\text { segurança em caso de um } \\
\text { imprevisto. } 10\end{array}$ & $\begin{array}{l}\text { Eu gosto de apostar em } \\
\text { imóveis como forma de fazer } \\
\text { o dinheiro render. } 8\end{array}$ & $\begin{array}{l}\text { Eu deveria conhecer melhor } \\
\text { os produtos de investimento } \\
\text { de maior risco. } 6\end{array}$ \\
\hline & $\begin{array}{l}\text { Queremos investimentos } \\
\text { conservadores porque não } \\
\text { temos interesse em entender } \\
\text { disso. } 7\end{array}$ & $\begin{array}{l}\text { A gente gosta de guardar o } \\
\text { dinheiro em caixinhas. Uma é } \\
\text { pra gente sair. A outra é para } \\
\text { adquirir. } 2\end{array}$ & \\
\hline
\end{tabular}

Fonte: Elaborado pela autora com base na pesquisa realizada a partir de Ozkaramanli e Desmet, 2012. 
No quadro, os concerns conflitantes foram identificados com cores diferentes (azul, vermelho), e os concerns significativos foram preenchidos com a cor cinza. Foram selecionados cinco concerns categorizados como objetivo (sinalizados com borda azul), um concern como atitude (borda vermelha) e quatro concerns como padrão (borda vermelha).

Como é possível observar, os concerns selecionados de objetivo/meta não apresentam conflitos entre si. Eles demonstram diferentes motivações de médio e longo prazo que se viabilizam com a economia de recursos financeiros. Dois concerns, por exemplo, destacam a preocupação com o futuro dos filhos: "eu quero que meu filho tenha uma poupança" e "quero muito dar alguma coisa para quando minha filha tiver 18 anos conseguir andar". Os demais, referem-se à conquista de bens ou de segurança e tranquilidade futura.

Porém, ao confrontar esses concerns de objetivos/metas com o de atitude e os de padrões/normas destacados, encontram-se diversos conflitos. Por exemplo, o concern "eu gosto de comprar aquilo que gostei, independente do preço" demonstra uma atitude contrária à meta de economizar dinheiro. Outros concerns de padrão, vão nessa mesma linha: "eu gostaria de não ser tão compulsiva e gastar tanto dinheiro", "eu deveria manter algum investimento, mas não consigo porque não tenho controle" e "eu não deveria esbanjar. Deveria dar mais valor ao meu dinheiro e pensar no futuro". Esses concerns dizem respeito ao descontrole das pessoas em relação ao uso do dinheiro, o que impede que consigam economizar e ter uma tranquilidade financeira. Elas optam pelo prazer imediato (consumir e fazer o que lhes satisfaz agora) em detrimento de uma meta ou objetivo futuro maior. Também demonstram que há um conflito de consciência entre o que deveria fazer e o que realmente faz, que pode ser relacionado a emoções negativas, como arrependimento e culpa.

$\mathrm{Na}$ seleção, foram priorizados os concerns relacionados aos estímulos de autofoco e de atividade em relação ao de produto. Isso porque o cumprimento de objetivos de alto nível é mais propenso a contribuir para a autorrealização (e, assim, provocar intensas experiências emocionais), em relação ao cumprimento de metas concretas (OZKARAMANLI e DESMET, 2012).

Além do perfil de concerns e os conflitos entre eles, foram destacados cinco padrões que podem ser relevantes e inspiradores para o projeto de design. As atitudes foram preteridas em relação aos padrões por se referirem apenas ao que os usuários gostam ou não, o que por si só, diz pouco sobre o raciocínio por trás das preferências (DEMIR, et. al. 2010). As declarações selecionadas demonstram o comportamento e emoções dos entrevistados em relação às finanças como, por exemplo, este concern que demonstra uma clara frustração por um objetivo não atendido: "eu gostaria de ter concluído uma formação superior, mas não consegui por falta de condições financeiras". Este outro concern, "Eu devo economizar todo mês, mesmo que seja pouco e mesmo que implique em abrir mão de algumas coisas" e os outros selecionados, carregam uma espécie de autojulgamento dos entrevistados em relação aos padrões nos quais acreditam que deveriam se enquadrarem. Isso demonstra que possuem conhecimento em relação ao que deve ser feito para atingir a meta/objetivo de longo prazo: manter um investimento para conquistas e tranquilidade futuras. Porém, nestas declarações, fica evidente que a tarefa não é fácil, exigindo sacrifícios. 


\section{CONSIDERAÇÕES FINAIS}

A presença de concerns conflitantes em relação à gestão financeira era esperada e foi confirmada. Além disso, os dados obtidos confirmaram alguns conceitos apresentados na revisão bibliográfica como, por exemplo, o de framing, que propõe o alocamento de recursos em diferentes contas. Ele aparece no relato de um dos casais e é representado pela seguinte declaração de concern: "a gente gosta de guardar o dinheiro em caixinhas. Uma é pra gente sair. A outra é para adquirir". Também é confirmado o perfil conservador dos brasileiros em relação a investimentos. Os entrevistados declararam dar preferência à segurança em detrimento da rentabilidade. Um exemplo nesse sentido é que imóveis são considerados um bom tipo de investimento, de maneira quase unânime entre os pesquisados. Outra questão evidenciada é a preocupação em evitar o pagamento de juros.

Vale observar que o período de vida (no caso, início da vida adulta) também interfere nas decisões financeiras. Os planos e projetos futuros têm como prioridade o bem-estar da família, com especial preocupação em relação aos filhos. Por último, o nível de renda não parece interferir na consciência da importância de poupar presente nos dois grupos. Porém, o esforço do grupo de menor renda concentra-se, primeiro, em conseguir fazer as contas caberem no orçamento. Assim, fica mais difícil "fazer sobrar" alguma quantia para economizar. O grupo de renda mais alta, já demonstra que manter uma reserva e planejar o futuro faz parte dos seus hábitos.

Os achados apresentados contextualizam a temática e identificam alguns concerns e conflitos, atendendo às etapas um e dois propostas pela literatura em estudo. Porém, o objetivo final é o de projetar uma solução, objetivando despertar ou evitar certas emoções a partir dos concerns conflitantes e significativos identificados.

Nesse sentido, a continuidade desse estudo deve focar na utilização do perfil de concerns construído e aplicá-los nas etapas três e quatro: perfil de produto e projeto de produto. O perfil de concerns será insumo para a ação projetual, na qual os designers terão que entender quais concerns estão impedindo que os objetivos sejam alcançados e criar uma solução que concilie ou minimize os conflitos. Os apontamentos trazidos pelos concerns significativos também poderão ser úteis para guiar o projeto na sua finalidade de estimular os usuários, no caso, os poupadores a buscarem seus objetivos de longo prazo. Para isso, os concerns deverão ser apresentados de maneira clara, criativa e inspiradora aos designers para que eles possam compreendê-los e, assim, explorá-los para projetar com foco nas emoções.

\section{REFERÊNCIAS}

ÁVILA, Flávia; BIANCHI, Ana M. (org.). Guia de Economia comportamental. Tradução Laura Teixeira Motta. São Paulo: Economia Comportamental, 2015.

BARBOSA, Livia. Sociedade de consumo. Rio de Janeiro: Jorge Zahar Editor, 2004.

BUCHANAN, Richard. Declaration by design: Rhetoric, argument, and demonstration in design practice. Design Issues, p. 4-22, 1985.

. Design research and the new learning. Design issues, v. 17, n. 4, p. 3-23, 2001.

CARDOSO, R. Uma introdução à história do design. São Paulo: Edgard Blucher, 2004. 
CARÙ, Antonella; COVA, Bernard. Consuming Experience. New York: Routledge, 2007. Confederação Nacional do Comércio de Bens, Serviços e Turismo (CNC). Pesquisa de Endividamento e Inadimplência do Consumidor (Peic), abril/2016. Disponível em: $<$ http://www.cnc.org.br/noticias/economia/percentual-de-familias-endividadas-caipara-596-em-abril>. Acesso em: 05 mai. 2016.

Confederação Nacional da Indústria (CNI)-IBOPE. Retratos da Sociedade Brasileira: Inclusão Financeira, 2012. Disponível em: <http://arquivos.portaldaindustria.com.br/ app/conteudo_24/2012/07/09/42/20120806210240175262u.pdf>. Acesso em: 10 jan. 2016.

DESMET, P. Designing emotions. Delft, The Netherlands. Tese de Doutorado. Delft University of Technology, 225 p. 2002.

P. Nine sources of product emotion. Proceedings of IASDR, [S.I.], n. 7, p. 1-15, 2007. Disponível em: <http://repin.pjwstk.edu.pl:8080/xmlui/bitstream/handle/ 186319/98/kansei2011_Desmet.pdf?sequence=3>. Acesso em: 21 set. 2015.

Three levels of product emotion. In: Proceedings of the International Conference on Kansei Engineering and Emotion Research. p. 236-246. 2010. ; HEKKERT, Paul. Special issue editorial: Design \& emotion. International Journal of Design, v. 3, n. 2, 2009.

DEMIR, E.; DESMET, P.; HEKKERT, P. Appraisal Patterns of Emotions in Human-Product Interaction. International Journal of Design, 3(2):41-51. 2009.

.; OZKARAMANLI, D.; DESMET, P. M. A. How to design for emotions:

experiences in a course. In: PROCEEDINGS OF THE INTERNATIONAL DESIGN \& EMOTION CONFERENCE, 7., 2010. Chicago. Anais... Chicago, 2010.

FERREIRA, Vera Rita de Mello. Psicologia econômica: estudo do comportamento econômico e da tomada de decisão. Rio de Janeiro: Elsevier, 2008.

FRIJDA, Nico H. The emotions: Studies in emotion and social interaction. Maison de Sciences de l'Homme. Paris,1986.

; Kuipers, P., \& Ter Schure, E. Relations among emotion, appraisal, and emotional action readiness. Journal of Personality and Social Psychology, 57(2), 212228, 1989.

KATONA, George. Psychological economics. New York: Elsevier, 1975.

MEIRELLES, Valéria M. Atitudes, crenças e comportamentos de homens e mulheres em relação ao dinheiro na vida adulta. Tese de Doutorado. PUC-São Paulo, 2012. Disponível em: http://www.valeriameirelles.psc.br/assets/tese_valeriameirelles.pdf. Acesso em: 21 set. 2015.

MERONI, Anna. Strategic design: where are you now? Reflection around the foundations of a recent discipline. Strategic Design Research Journal, volume 1, número1, julho-dezembro 2008.

NYHUS, Ellen K. Psychological determinants of household saving behaviour. Tese de doutourado. Norwegian School of Economics and Business Administration. Bergen, 2002. 
OZKARAMANLI, Deger; DESMET, Pieter MA. I knew I shouldn't, yet I did it again! Emotion-driven design as a means to motivate subjective well-being. International journal of design, 6 (1), 2012.

PAPALIA, D.E; OLDS, S.W; FELDMAN, R.D. Desenvolvimento Humano. Tradução: Carla F. M. Pinto Vercesi [et al]. 10a . ed. RS: Porto Alegre: Artes Médicas McGrawHill, 2010.

SCHERER, K. R. Appraisals considered as a process of multilevel sequential checking. In K. Scherer, A. Schorr, T. Johnstone (Eds.), Appraisal processes in emotion: Theory, methods, research. New York: Oxford University Press, 2001.

SECRETARIA DE ASSUNTOS ESTRATÉGICOS DA PRESIDÊNCIA DA REPÚBLICA. A Classe Média Brasileira. Brasília: N. 1, nov. 2014. Disponível em: <http://www.sae.gov. br/wp-content/uploads/ebook_ClasseMedia1.pdf>. Acesso em: 02 de nov. 2015.

SHEFRIN, Hersh M.; THALER, Richard H. The behavioral life cycle hypothesis. Economic inquiry, v. 26, n. 4, p. 609-643, 1988.

SURI, F. The experience of evolution: developments in design practice. The Design Journal, 6(2):39-48, 2003.

VERGANTI, R. Design, meanings, and radical innovation: A metamodel and a research agenda. Journal of product innovation management, v. 25, n. 5, p. 436-456, 2008. 